\title{
Avoid the embarrassment: Use the right tools for the right job
}

\author{
Stephen S. Steele, MD \\ Queen's University, Kingston, ON, Canada
}

Cite as: Can Urol Assoc J 2017;11 (3-4):111. htrp://dx.doi.org/10.5489/cuaj.4517

See related article on page 104.

A sk a room full of urological surgeons the indications for cystoscopy and urodynamics (UDS) and you are likely to get a multitude of rationales for each test. These tests are invasive, painful, and downright embarrassing to our patients.

There is no doubt that cystoscopy and UDS, if used correctly, have a proper purpose in helping diagnose and ultimately treat our patients. There are definitely valid indications for both tests, but have we reached a point in the urological community where we may be performing and ordering diagnostic tests that are not required and make little to no difference in the outcome or treatment algorithm of our patients?

Few would argue that there are several hard and fast reasons to perform cystoscopy on our patients, such as those with gross hematuria or in followup of high-risk bladder cancer. But what about other, softer indications? Published data would suggest that many cystoscopies that urologists perform could be avoided.

The data seem pretty clear that cystoscopy in patients with stress urinary incontinence is of low yield and can likely be omitted. ${ }^{1}$ But what about patients with overactive bladder, recurrent urinary tract infections (UTIs), and male lower urinary tract symptoms (LUTS). For the majority of men, cystoscopy for the investigation of LUTS can be avoided. ${ }^{2}$ The data suggest there is really only a need for cystoscopy in men with LUTS to exclude suspected bladder or urethral pathology and/or before minimally invasive surgical therapies if the findings may change treatment. ${ }^{2}$ Otherwise it is not necessary. The same holds true for recurrent UTIs in women. Cystoscopy performed solely for recurrent UTI is low-yield in the majority of patients. ${ }^{3}$ Data is also emerging that even those with low-risk bladder tumours need only annual surveillance; ${ }^{4}$ bladder augments don't need yearly cystoscopy ${ }^{5}$ and the list goes on.

The same holds true for UDS. Too often it is ordered for all types of incontinence and voiding dysfunction in women when, in reality, it really only needs to be done in women with urge incontinence refractory to treatment or recurring urge incontinence. ${ }^{6}$ For those with urge incontinence, it should not be performed in a woman with previously untreated symptoms of urge urinary incontinence without neurological disease. ${ }^{6}$

Unfortunately, we are often too quick to jump to invasive technological studies and tests when simple treatments should be employed first. That is not to say that we should not use all the resources we have at our disposal to treat our patients, just that we need to use them for the right indications, which will ultimately have an impact on our patients' lives. Used properly cystoscopy and UDS are invaluable tools in diagnosing and directing proper patient treatment. However, used improperly they are nothing more than expensive procedures that do little for our patients other than causing them pain and embarrassment.

Competing interests: The author reports no competing personal or financial interests.

\section{References}

1. Abrams $\mathrm{P}$, Andersson $\mathrm{KE}$, Birder L, et al. Fourth International Consultation on Incontinence Recommendations of the International Scientific Committee: Evaluation and treatment of urinary incontinence, pelvic organ prolapse and fecal incontinence. Neurourol Urodyn 2101;29:213-40. https://doi.org/10.1002/nau.20870

2. Gratzke $C$, Bachmann $A$, Descazeaud $A$, et al. EAU guidelines on the assessment of non-neurogenic male lower urinary tract symptoms including benign prostatic obstruction. Eur Urol 2015;67:1099-109. https://doi.org/10.1016/j.eururo.2014.12.038

3. Pagano MJ, Barbalat $Y$, Theofanides MC, et al. Diagnostic yield of cystoscopy in the evaluation of recurrent urinary tract infection in women. Neurol Urodyn 2016. [Epub ahead of print].

4. Kassouf W, Traboulsi SL, Schmitz-Dräger B, et al. Followup in non-muscle-invasive bladder cancer International Bladder Cancer recommendations. Urol Oncol 2016;34:460-8. https://doi.org/10.1016/j. urolonc.2016.05.028

5. Hamid R, Greenwell TJ, Netherliffe JM, et al. Routine surveillance cystoscopy for patients with augmentation and substitution cystoplasty for benign urological conditions: Is it necessary? BJU Int 2009; 104:392-5. https://doi.org/10.1111/i.1464-410X.2009.08401.x

6. Anger J, Scott VC, Kiyosaki K, et al. Development of quality indicators for women with urinary incontinence. Neurourol Urodyn 2013;32:10.1002.

Correspondence: Dr. Stephen S. Steele, Queen's University, Kingston, ON, Canada; steeles@KGH.KARI.NET 